\title{
Safe Driving - Assessment Mechanism to Reduce Morbidity and Mortality: A concept paper with reviewing a clinical case
}

\author{
Mendis NDNA* \\ Department of Forensic Medicine and Toxicology, Faculty of Medicine, University of Colombo, Sri Lanka.
}

\begin{abstract}
Introduction
Where a vehicle driver has multiple conditions or a condition that affects multiple body systems, there may be an additive or a compounding detrimental effect on driving abilities. An 81-year-old male motorcyclist was admitted to a tertiary care hospital following a road traffic accident. He has sustained only minor injuries. No significant past medical history. He has monocular vision since 1960 following accidental trauma to the right eye. He had obtained a heavy and light vehicle driving license in 1958, which is valid for life. Driving with monocular vision is permitted in many European countries and Sri Lanka. However, an important question remains - should the ability of driving be reviewed in an accident or any other condition which affects driving. This paper attempts to propose a referral mechanism to reduce morbidity and mortality in people with driving disabilities. Monocular vision affects vision in many ways. This might have serious implications both on the safety of the patient and the public. Driving with monocular vision is allowed in many countries. However proper evaluation of subsequent illnesses and referral mechanism is important in cases like this to reduce morbidity and mortality. In Sri Lanka there is no proper referral system for this. Therefore, we propose to introduce 1. Mandatory renewal of all driving licenses. 2. Mandatory notification system in conditions that affect driving 3. Issue a restrictive license and frequent review in relevant cases. This would be important in reducing injury risk to both the individual concerned and the public.
\end{abstract}

Keywords: Driving license, Law, Monocular vision

Received: 10 May 2021, Revised version accepted: 27 June 2021, Published: 30 June 2021. *Corresponding author: Mendis NDNA, \Email: asela@fortox.cmb.ac.lk, (Dttps://orcid.org/0000-0002-4690-9493

Cite this article as: Mendis NDNA. Safe Driving - Assessment Mechanism to Reduce Morbidity and Mortality: A concept paper with reviewing a clinical case. Medico-Legal Journal of Sri Lanka, 2021;9(1):44-46.

DOI: http://doi.org/10.4038/mljsl.v9i1.7440

Copyright: @ 2019 with the Medico-legal Journal of Sri Lanka.

This is an open-access article distributed under the terms of the Creative Commons Attribution 4.0 International License, which permits unrestricted use, distribution and reproduction in any medium provided the original author and source are credited.

\section{Introduction}

According to the WHO data published for the year 2018, road traffic accident deaths in Sri Lanka is around 3590 or accounting for $2.8 \%$ of total deaths.[1]

The causes of RTAs are multifactorial. However, the main cause of this is due to human factors. While driving, the drivers process information through visual inputs $(90 \%)$, auditory inputs, or internal inputs.[2] Multiple conditions such as congenital disabilities (e.g. cerebral palsy, spina bifida), multiple trauma leading to neurological and orthopaedic injuries, aging-related changes, drug and alcohol addiction and multi-system disease (e.g. HIV, Diabetes) that affects multiple body systems, effect on driving abilities of an individual.[3] Globally the major causes of visual impairment are cataract and diabetic retinopathy.[4,5]
Driving with monocular vision is permitted in many European countries and also in Sri Lanka (SL). For some medical conditions, a conditional license with appropriate vehicle modifications is granted in SL.[6]

In SL Since 2012, medical fitness to drive is assessed by National Transport Medical Institute (NTMI). There is a national guideline on assessing medical fitness to drive. The commonest medical condition identified during the medical examinations at the NTMI $(53,655$ cases from 877,243 examinations in 2018) is visual problems.[7] The vision standards for driving licenses vary from country to country.[8] In Sri Lanka, the visual acuity, visual fields, presence of eye conditions such as nystagmus, squints, diplopia and progressive eye diseases are considered under 
vision.[6] Colour blindness has no restrictions for driving in Sri Lanka.[6]

According to the guidelines provided by the College of Eye Surgeons along with NTMI there are certain criteria for the issue of a driving license to a person with monocular vision.[6]

(a) Visual acuity in the worse eye less than $6 / 12$ is contraindicated for commercial passenger transport vehicles and all heavy vehicles,

(b) Visual acuity in the worse eye $6 / 60$ or less than $6 / 60$ is absolutely contraindicated for threewheelers and motorcycles.

(c) visual acuity in worse eye $6 / 60$ or less than $6 / 60$, a conditional license with appropriate vehicle modifications are granted for light vehicles for personal use (not for commercial passenger transport).

This also emphasizes the requirement of higher visual standards for heavy and commercial vehicle licenses.[6]

\section{Objectives}

The Objective of this paper to propose a possible referral mechanism to reduce morbidity and mortality in people with driving disability.

\section{Background history}

An 81-year-old male motorcyclist was admitted to a tertiary care hospital following a road traffic accident. He has sustained only minor injuries. No significant past medical history. He has monocular vision since 1960 following accidental trauma to the right eye. He had obtained a heavy and light vehicle driving license in 1958, which is valid for life. There is a history of the patient meeting with repeated accidents since 1960 .

This case highlights an important question - should the ability of driving be reviewed regularly or at least after meeting with an accident resulting in injuries. In addition, if a medical condition affecting vision is diagnosed subsequently should it be informed to the relevant authorities.

\section{Discussion}

Once a driving license is granted, further monitoring of the license holder is done through real time testing where the driver's ability to drive in various life circumstances and stressors on the road is recorded and assessed over a period of time in certain countries.[9] In some countries, if a patient's condition is found to affect their ability to drive safely, the health professional may notify the condition to the driving license authority through a standard notification form.[3]

The process of proper documentation, record keeping and reporting to the driving license authority as appropriate helps to monitor the license holder.

Even though there is a process of license renewal for heavy and light vehicle licenses in SL, some people still have heavy and light vehicle licenses that are valid for life, which does not need renewal or medical tests. Therefore, even if a license holder was physically fit at the time of obtaining the license originally, any subsequent medical condition i.e., loss of sight in one eye, will not be subject to be checked and such a person will keep on driving till an accident happens or is detected by a police officer. Monocular vision affects vision in many ways. This might have serious implications both on the safety of the patient and the public.

\section{Conclusions and recommendations}

However, the proper evaluation of subsequent illnesses and referral mechanism is important in cases like this to reduce morbidity and mortality. In Sri Lanka there is no proper referral system for this. Therefore, we propose to introduce.

(1) Mandatory renewal of all driving license,

(2) Mandatory notification system in conditions that affect driving (Figure 01) and

(3) Issue a restrictive/conditional license and frequent review in relevant cases.

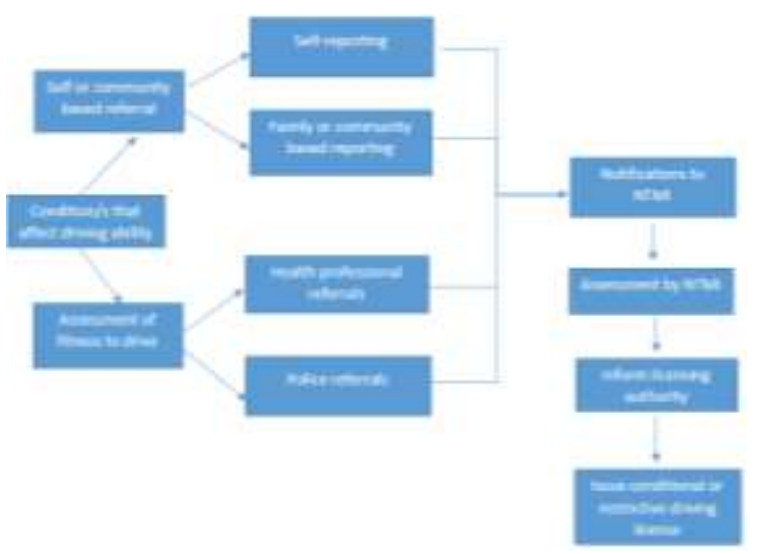

Figure 01: Proposed notification system in conditions that affect driving.

The time of renewal of the driving license also provides a golden opportunity to screen for many chronic age-related disorders (e.g., glaucoma). The appropriate modification of the existing laws as above and proper implementation is necessary to minimize vision-related RTAs, which is an avoidable cause of morbidity and mortality. This 
would be important in reducing injury risk to both the individual concerned and the public. Therefore, this serious issue needs immediate legislative and societal attention.

\section{Disclosure statement}

Conflicts of interests: The authors declare that they have no conflicts of interests.

Funding: None

\section{References}

1. Road Traffic Accidents Part- I, Weekly Epidemiological Report, Vol. 48 No. 07 06th 12th February 2021, p.1-2

2. Chakrabarty N, Lakshman A, Gupta K, Bhatnagar A. Visual challenges among drivers: A case study in Delhi, India. Int J Innov Res Sci Eng Technol 2013;2(7) :3074-83.

3. Assessing Fitness to Drive, Available from: https://austroads.com.au/publications/assessing -fitness-to-drive/ap-g56/principles-ofassessing-fitness-to-drive/medical-conditionsand-driving/multiple-medical-conditions-anddqcc9eo- (accessed on 26.06.2021)

4. National Society to Prevent Blindness. Visual Problems in the US Data Analysis Definitions, Data Sources, Detailed Data Tables, Analysis, Interpretation. New York: National Society to Prevent Blindness; 1980. pp. 1-46.

5. Behboudi H, Moghadam RS, Tiefeh N, Karkan MF. Vision Disorders in Drivers Involved in Traffic Accidents. J Ophthalmic Vis Res. 2017;12(4):451-452. doi: 10.4103/jovr.jovr_ 16917

6. College of Ophthalmologists of Sri Lanka. Vision Standards for Driving License in Sri Lanka. Available from: https://www.cosl.lk/ pdf/

Vision_standards_Driving_license_Sri_Lanka. pdf (accessed on 26.06.2021)

7. Ministry of Transport and Civil Aviation. Statistics - medical examinations in 2018.

Available from: http://www.transport.gov.lk/ web

/index.php?option $=$ com_content\&view $=$ article $\& \mathrm{id}=240 \&$ Itemid $=169 \&$ lang $=$ en. $\quad$ (Accessed On 26.06.2021)

8. Murthy, Gowri J; Deshmukh, Ajinkya V; Mallidi, Ayyappa R; Murthy, Praveen R1; Kattige, Jyoti S; Murthy, Vinay R2 Renewal of driving license in India and glaucoma, Indian Journal of Ophthalmology: 2019;67(2):240-6. doi: 10.4103 /ijo.IJO_776_18

9. International Council of Ophthalmology. Visual standards; vision requirements for driving safety with emphasis on individual assessment. Report prepared for the International Council of Ophthalmology at the 30th World Ophthalmology Congress. Sao Paulo, Brazil, February 2006.Available from: http://www.icoph. org/ enhancing_eyecare/ standards_for_eyecare_and_vision.html. (accessed on 26.06.2021) 